NISTIR 6619

\title{
Failure Analysis of the WWVB Tower
}

J. D. McColskey

C. N. McCowan

R. L. Santoyo

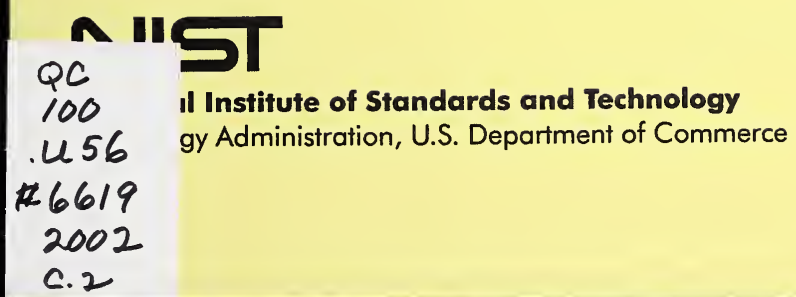





\section{Failure Analysis of the WWVB Tower}

J. D. McColskey

C. N. McCowan

R. L. Santoyo

Materials Reliability Division Materials Science and Engineering Laboratory National Institute of Standards and Technology

325 Broadway

Boulder, Colorado 80305

August 2002

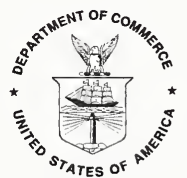

U.S. Department of Commerce Donald L. Evans, Secretary

Technology Administration Phillip J. Bond, Under Secretary of Commerce for Technology National Institute of Standards and Technology Arden L. Bement, Jr., Director 


\title{
Failure Analysis of the WWVB Tower
}

\author{
J.D. McColskey, C.N. McCowan, R.L. Santoyo \\ National Institute of Standards and Technology \\ Materials Reliability Division \\ Boulder, CO 80305
}

\begin{abstract}
A failure analysis was conducted on the collapse of the NIST WWVB tower. The analysis included mechanical testing, chemical analysis, and metallographic examination of the failed part. We ascertained that the underlying reason for the collapse was fatigue failure due to poor engineering design and improper specifications on the insulator pin. Based on our findings, we recommend new pins be fabricated using recommended engineering practices with particular attention paid to details such as tolerances, radii, material choice, and heat treatment procedures.
\end{abstract}

Key words: collapse, failure analysis, fatigue, fillet, insulator pin, stress concentration, tower, support pin. 


\section{Executive Summary}

On February 27, 2001, the uppermost $30 \mathrm{~m}$ of the $122 \mathrm{~m}$ high NIST WWVB tower collapsed due to the failure of an insulator pin that supported the upper part of the tower. The Materials Reliability Division of the Materials Science and Engineering Laboratory of NIST was asked to conduct an investigation into the cause of the failure. A rapid assessment was needed, since WWVB is a highly visible NIST service and a return to full-power operation was necessary to maintain nationwide coverage. The WWVB tower continuously broadcasts time and frequency signals at $60 \mathrm{kHz}$ throughout North America. These signals automatically synchronize electronic products such as wall clocks, clock radios, and wristwatches used by millions of people in the United States. In addition, the signals are used for high-level applications such as network-time synchronization and frequency calibrations. This report summarizes the results of our evaluation and makes recommendations for the design of future insulator pins.

The failed support pin was from one of four groups of nine that support the towers at the WWVB transmitter facility. The towers, originally constructed in 1962, were refurbished in 1999 and the pins, used to accommodate an insulator on the guy wires, were replaced. Thus, the failed pin had been in service only 2 to 3 years compared with 37 years for the old pins.

Initial examination of the failed pin showed that failure was initiated by fatigue. The fatigue crack was located in the radius of the head-to-shank fillet of the pin. Visual, chemical, and microscopic metallurgical examinations of the pin were performed. The conclusion was that a fatigue crack initiated at the fillet and propagated across the pin diameter until the remaining pin area was no longer capable of sustaining the loads imposed by the tower, resulting in catastrophic failure. This process likely occurred because the new pin had a fillet radius approximately half that of the old pins, increasing the stress concentration in the shank-to-head transition region. In addition, circumferential tool marks, tool chatter, and surface pitting provided numerous locations at which the stress concentration was further increased in the fillet radius and may have served as initiation sites for fatigue cracks.

\section{Background Information}

The $122 \mathrm{~m}$ WWVB tower, outside Ft. Collins, CO, was damaged on February 27, 2001, because of a failure of a steel pin, $38 \mathrm{~mm}$ (1.5 in) in diameter, that connected the top-level guy wire of the tower to its concrete anchor. The failed pin was one of nine on each of four towers. This pin had a length of $61 \mathrm{~cm}(24 \mathrm{in})$, but pins $46 \mathrm{~cm}$ (18 in) long with a diameter of 


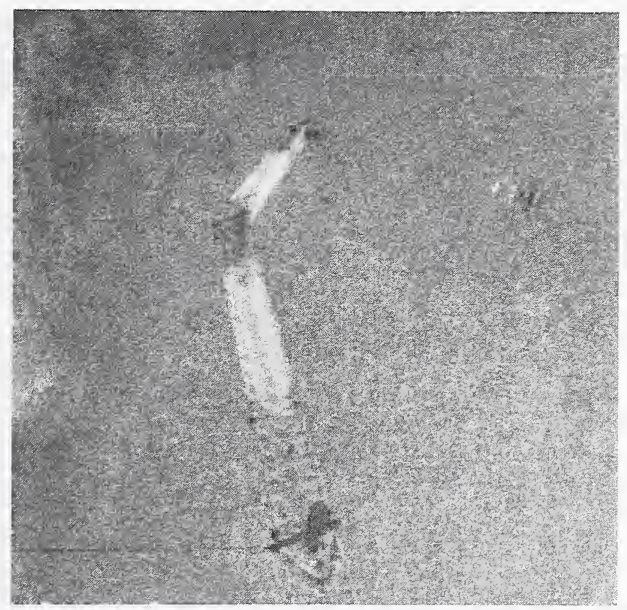

Figure 1: Photo shows results of failure of insulator pin. Upper portion of tower had to be replaced and new pins replaced.

$31.75 \mathrm{~mm}$ (1.25 in) diameter were also present on the tower. The shorter pins were used in locations that were not as highly stressed as the longer pins of larger diameter. Since the larger pin was the one that failed, when this report refers to a pin, it refers to the larger pin.

The failure resulted in a collapse of the uppermost $30 \mathrm{~m}$ of the $122 \mathrm{~m}$ tower as shown in figure 1 . The tower, originally constructed in 1962, was refurbished in late 1999 when new pins replaced the old pins. The new pins had been in service approximately 2 to 3 years when failure occurred. The old pins had been in service approximately 37 years with no failures. The pins were connected to guy wires supporting the towers, via Lapp* insulators, and anchored to concrete bases via clevis-pin attachments (figs. 2 and 3 ).

The WWVB tower continuously broadcasts time and frequency signals at $60 \mathrm{kHz}$ throughout North America. The signals are used for high-level applications such as time synchronization and frequency calibrations. The signals are also used by millions of people in the United States for time synchronization of electronic products such as clocks, clock radios and wristwatches. The tower was capable of operation at reduced power while repairs were made and a failure analysis was conducted.

\footnotetext{
* Trade name is included for information only; it does not imply recommendation or endorsement by NIST, nor does it imply that the mentioned products are necessarily the best available for the purpose.
} 


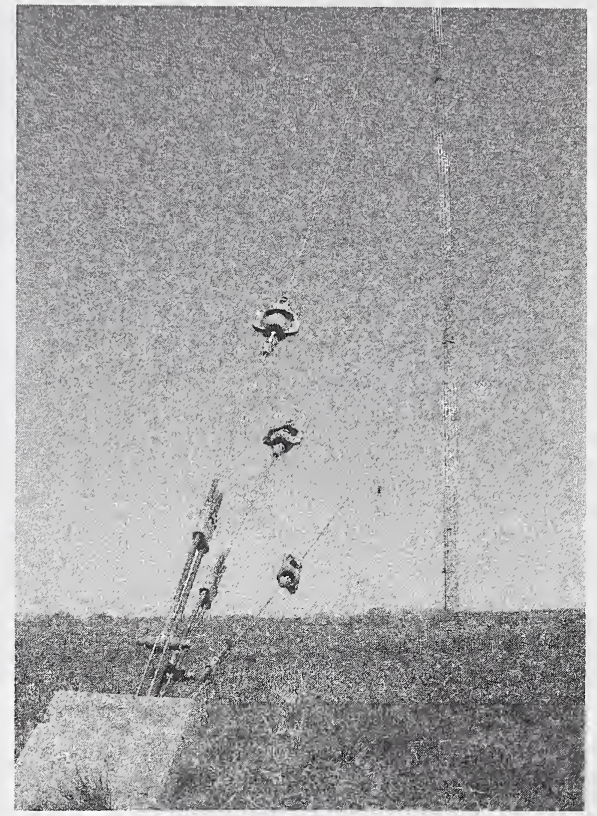

Figure 2: Photo shows guy wires, Lapp insulators with pins, and concrete anchors.

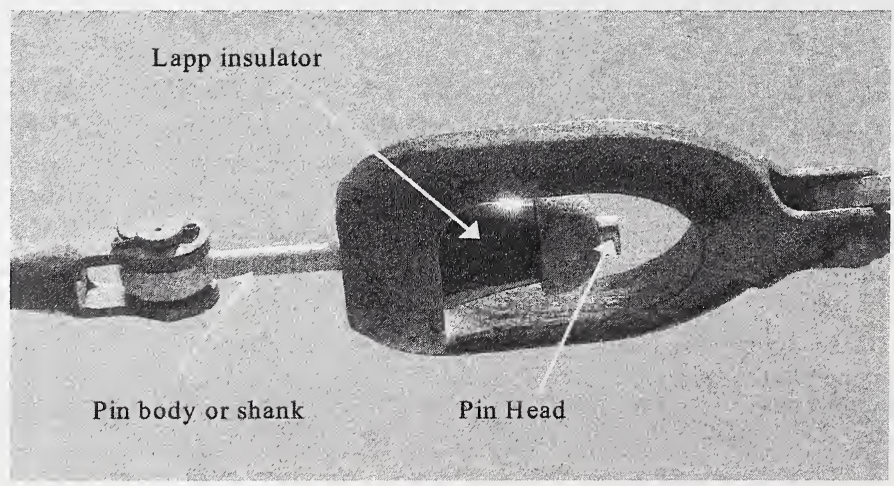

Figure 3: Close-up of Lapp insulator and pin arrangement. 
According to information provided by the operators of the tower (and others interviewed for this report), the new pins were to be made according to the design of the old pins. To accomplish this, the contractor specified on the drawings in Figure A.2 that the new pins were to be fabricated from "carbon steel with a breaking strength of 100,000 pounds," for the long pins. The contractor-supplied drawings used for construction of the new pins are shown in Appendix A. It is not clear as to who chose the "carbon steel" to be used for the pins, or what specific production methods were to be used for the fabrication of the pins. However, we know that the new pins were forged from AISI 4140 steel, which is a $0.4 \%$ carbon steel that contains between 0.80 and $1.1 \% \mathrm{Cr}$, and between 0.15 and $0.25 \% \mathrm{Mo}$. (Strictly speaking, an AISI 4140 steel is not a "carbon steel" but an "alloy steel." Carbon steels are designated as $1 \mathrm{xxx}$ numbers in the AISI system and do not contain a specified range for chromium and molybdenum as $41 \mathrm{xx}$ steels do.) The forging process that was used in the manufacture of the AISI 4140 alloy steel new pins was described as upset forging and shaping of a bar $50 \mathrm{~mm}(2 \mathrm{in})$ in diameter at $1149^{\circ} \mathrm{C}\left(2100{ }^{\circ} \mathrm{F}\right)$, normalizing at $871{ }^{\circ} \mathrm{C}(1600$ ${ }^{\circ} \mathrm{F}$ ), and air-cooled [1]. Although AISI 4140 is typically quenched and tempered, there was no quench and temper specified on these parts. This may have been because the AISI 4140 already met the strength requirement without the additional heat treatment. Also, according to reference [1], the AISI 4140 pins were forged, machined, electroplated, sent out for use, and found to have too small an inner diameter in the eye. The pins were returned and the plating was stripped, the eye re-machined and the pins plated again. The pins were then returned and put into service.

The failed pin supported the northernmost tower in the tower array. It was aligned with the prevailing winds (NW direction) in such a way that the pin was more highly loaded when the prevailing winds were blowing. This particular pin supported the top-most part of the tower and was probably the most highly stressed pin on this tower because of the prevailing winds. The winds on the day of failure were 8 to $24 \mathrm{~km} / \mathrm{h}(5$ to $15 \mathrm{mph})$, from a northeasterly direction, and the temperature was approximately -9 to $-4{ }^{\circ} \mathrm{C}\left(15\right.$ to $\left.25^{\circ} \mathrm{F}\right)$ and falling.

In order to determine the cause of this premature failure, the Materials Reliability Division of the National Institute of Standards and Technology conducted a failure analysis on the broken steel pin.

\section{Visual Examination of the Failed Pin}

The new pin failed in the radius of the shank-to-head fillet, as shown in figures 4 and 5 . Visual examination of the fracture surfaces indicated failure was initiated by fatigue. The fatigue crack grew until the remaining ligament had insufficient area to support the loads imposed on the pin. Numerous small pits on the surface, as well as some circumferential tool marks covered the surface along the shank of the pin and some regions of the radius area. The fact that the pins were made from $50 \mathrm{~mm}$ diameter stock brings into mind the question of the origin of the many pits found on the surface of the shank and fillet of the pin. It is unlikely that the pits and other surface defects were part of the original surface of the stock. It is more likely these flaws occurred during the fabrication of the pins. 


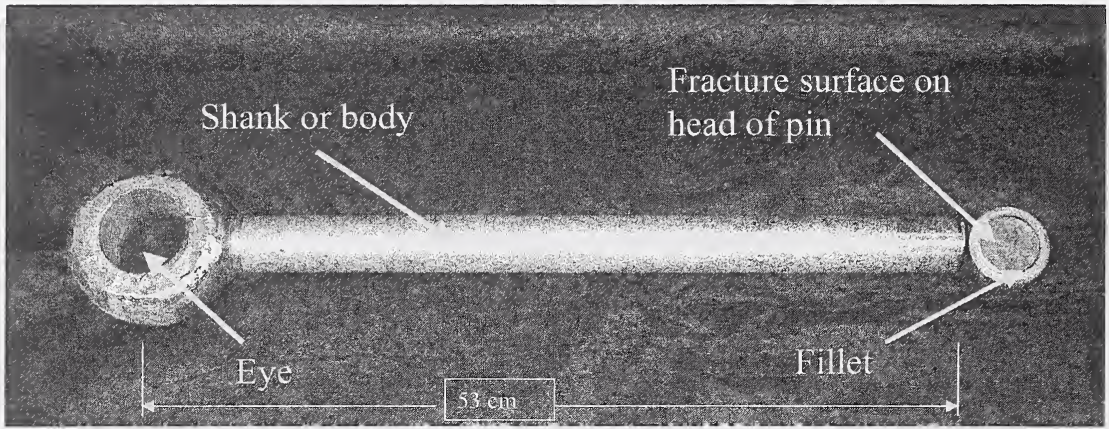

Figure 4: The new pin with failure in the radius of the shank-to-head fillet. The fracture surface can be seen on the head at the right end of the photo.

\section{Chemical Analyses}

Chemical analyses on one of the old and two of the new pins showed that they were respectively AISI 1030 and AISI 4140 steels. The corrosion-resistant plating on both pin types was determined to be zinc. Detailed results of the chemical analyses are given in Appendix B.

\section{Mechanical and Nondestructive Testing}

Hardness tests were conducted on both pin types. Results show that the old pin had a hardness of $80 \mathrm{HRB}$ and the new pin had a hardness of about $105 \mathrm{HRB}$ (28.5 HRC). So, the new pin is harder than the old pin and presumably stronger. The hardness data would indicate an ultimate tensile strength of about $510 \mathrm{MPa}(74 \mathrm{ksi})$ for the AISI 1030 and about $924 \mathrm{MPa}$ (134 ksi) for the AISI 4140. 
Tensile tests were conducted on both pin types in accordance with ASTM E-8, "Standard Test Methods of Tension Testing of Metallic Materials." Five tensile samples were machined from the longitudinal axis of the shank of each pin type. The five-sample-averaged tensile test results are shown in Table 1.

Table 1. Results of tensile tests.

\begin{tabular}{llllll}
\hline Pin type & Steel & $\begin{array}{l}\text { YS, MPa } \\
(\mathrm{ksi})(0.2 \%)\end{array}$ & $\begin{array}{l}\text { UTS, MPa } \\
(\mathrm{ksi})\end{array}$ & $\begin{array}{l}\text { Elongation, } \\
\%\end{array}$ & $\begin{array}{l}\text { Reduction of } \\
\text { area, } \%\end{array}$ \\
\hline Old & AISI 1030 & $336(48.8)$ & $558(80.9)$ & 30.2 & 59.8 \\
New & AISI 4140 & $738(107.1)$ & $995(144.3)$ & 14.7 & 48.4 \\
\hline
\end{tabular}

The thermal history of the old AISI 1030 steel pins was not available, but the data generated from the tensile tests conducted on the 1030 carbon steel show good agreement with published data [2] for the hot-rolled carbon steel. The tensile data could not be compared with other data for the forged AISI 4140 steel because of the lack of published data on forged 4140 steel with no quenched and tempered treatment. The new pins are almost twice as strong as the old pins.

Nine of the new pins were inspected for cracks using a dye-penetrant method. The zinc coating was removed in order to have access to the bare metal. No cracks were found in any of the pins inspected.

\section{Metallography}

Metallographic samples from the failed pin, and from the new and old pins were prepared. Samples were etched with a $3 \%$ nital solution to show microstructural details. Optical and scanning electron microscopes (SEM) were used to examine the samples. Energy dispersive $\mathrm{x}$-ray analysis (in the SEM) was used to qualitatively determine the composition of the coating on the new pins (labeled as N1, N2, etc.). Sample identifications are given in figure 5 .

The pin failed because a fatigue crack initiated at the radius machined under the head of the pin, and this crack grew until the cross-sectional area of the pin was decreased to an area that was too small to carry the applied tensile load. As shown in figure 6, beach marks are present on the fracture surface. The presence of beach marks identifies this as a fatigue failure [3]. The beach marks can occur as a result of changes in loading, environmental effects, and other factors that influence the crack growth and/or appearance of the surfaces of the crack faces. 
The beach marks are centered about the origin of the crack, indicating that the crack that caused this failure initiated in the region marked by the arrow. The rougher surface appearance in the lower portion of the figure is the final fracture region. Final fracture, or overload fracture, occurred when the cross-sectional area of the pin was reduced by fatigue cracking to an area no longer sufficient to carry the applied load. Once the critical stress was reached, the pin failed by rapid, catastrophic fracture.

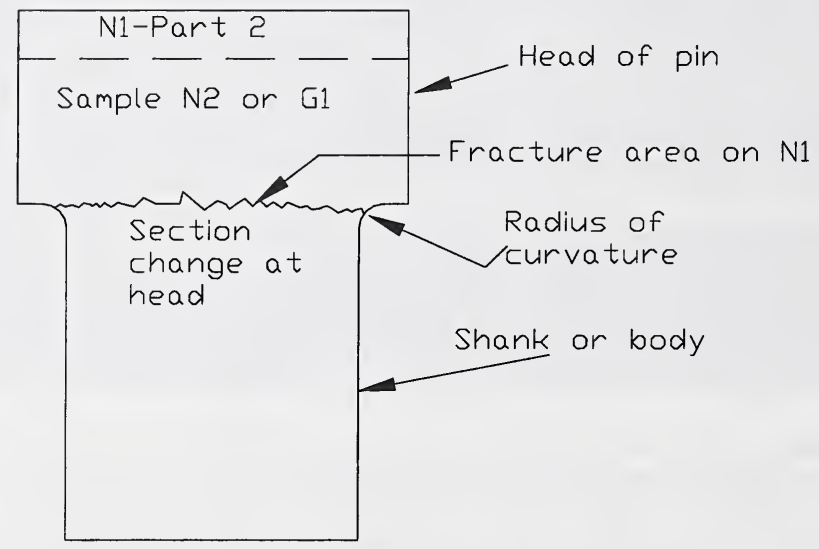

Figure 5: Diagram showing the cross-sectioned plane that was ground parallel to the longitudinal axis on the N2 and G1 pin samples for evaluations. The key feature is the transition from shank to head. The radius of curvature is indicated. The dashed line in the upper part of the head indicates where horizontal slices were made for metallography on N1part 2. 


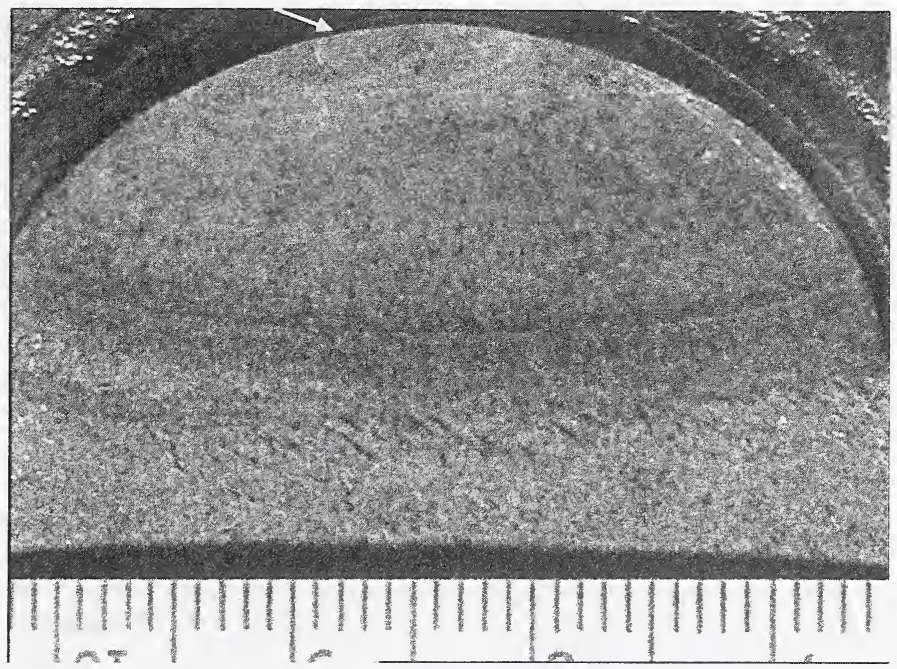

Figure 6: Fractured surface of the insulator pin. The arrow points to the fatigue crack origin. The scale at the bottom of the figure is in millimeters.

To help identify reasons why a large fatigue crack initiated and grew in the pin, we considered both design and material issues. Geometrical stress-concentrations are a wellknown site of initiation of fatigue cracks. The severity of such stress-concentrations is analyzed by considering, among other features, the exterior radius of curvature along the axis of maximum stress. A smaller radius of curvature results in a more severe stressconcentration. The stress-concentration in question here is the section change where the pin shank meets the head. Figure 5 shows the location and orientation of this stress-concentration relative to the whole pin. In figures 7 and 8 , the radii of the old and new pins are shown respectively. The radii of the new pins that we measured were significantly smaller than that used for the original pins. The old pins had a radius of $4.76 \mathrm{~mm}(0.1875 \mathrm{in})$ and the new pins had radii that ranged from $1.9 \mathrm{~mm}(0.07 \mathrm{in})$ to $2.9 \mathrm{~mm}(0.11 \mathrm{in})$. A smaller radius increases the stress-concentration, which increases the likelihood for initiation of fatigue cracks. In addition, there were multiple pits in the bar including many in the radius area, which could have served as stress raisers on the surface of the new pin.

Differences in the type and quantity of surface flaws were observed on the new and old pins. As shown in figures 9 and 10 , the surface of the steel used for the old pins is relatively planar and free of defects, compared with the surface typical of the new pins. The old pins have a hot-dip galvanized coating that is about $100 \mu \mathrm{m}$ thick and the new pins have a $10 \mu \mathrm{m}$ thick electroplated zinc coating. Also note in figure 10 that the interface between the steel and the 
coating is wavy and irregular on the new pin, much different from that seen in the previous figure of the old pin. The new pins had numerous pits on the surface, along the shank as well as in the radius. In figure 11, three pits on the surface of the N2 sample are shown in the cross-section. These pits are near the radius at the head of the pin. We estimate the radius of these pits to be about $100 \mu \mathrm{m}$, so they clearly provide high local stress-concentrations. The surface pitting may be the result of improper pickling prior to electroplating or other steps involved in removing the original zinc coating. The pits in the AISI 4140 steel pins occurred sometime between the time they were forged and machined from $50 \mathrm{~mm}$ stock and the second time they were electroplated, because the $\mathrm{Zn}$ coating is present on the outside surface of the flaws.

The machined surfaces of the new pins also have circumferential tool marks along the length of the shank and in the head-to-shank radius, as seen in figure 12.

The new and old pins have different microstructures, as shown in figures 13 and 14 . The old steel has a mixture of equiaxed ferrite grains and regions of pearlite, which is indicative of plain carbon steel with good ductility. The new steel has a coarse structure, as shown in figures 15 and 16. It is interpreted to contain plates of ferrite and upper bainite, which is not a microstructure that is associated with good fracture toughness [4]. This structure is consistent with that which would be expected for air-cooling of the 4140 alloy from the forging temperature, which is how the pins were made [1].

Figures 17 to 21 relate the microstructure of the failed pin to the fracture surface. The fracture features observed on the surface of the fatigue crack indicate a somewhat tortuous crack path, with details that reflect the complex arrangement of the plate-like phase constituents in the steel. These details are most clearly shown in figures 18 and 19. Grain orientation and the microstructural constituents of the steel affect the growth of the fatigue crack. Some corrosion products are present on the surface of the fatigue crack, as expected, due to slow crack growth and exposure to environment and/or failure to protect the fracture surface following failure. In figures 20 and 21 , the fracture surface features of the overload region of the pin are shown. Quasi-cleavage features that are indicative of brittle fracture in steel dominate these regions, which is somewhat surprising. One would expect to observe a more ductile fracture mode for 4140 steel. However, since this pin apparently consists of upper bainite rather than tempered martensite, a brittle fracture is conceivable. Typically, a 4140 steel forging would be specified to have a quench-and-temper heat treatment rather than to be air-cooled. This would be expected to increase the toughness for a given level of strength. 


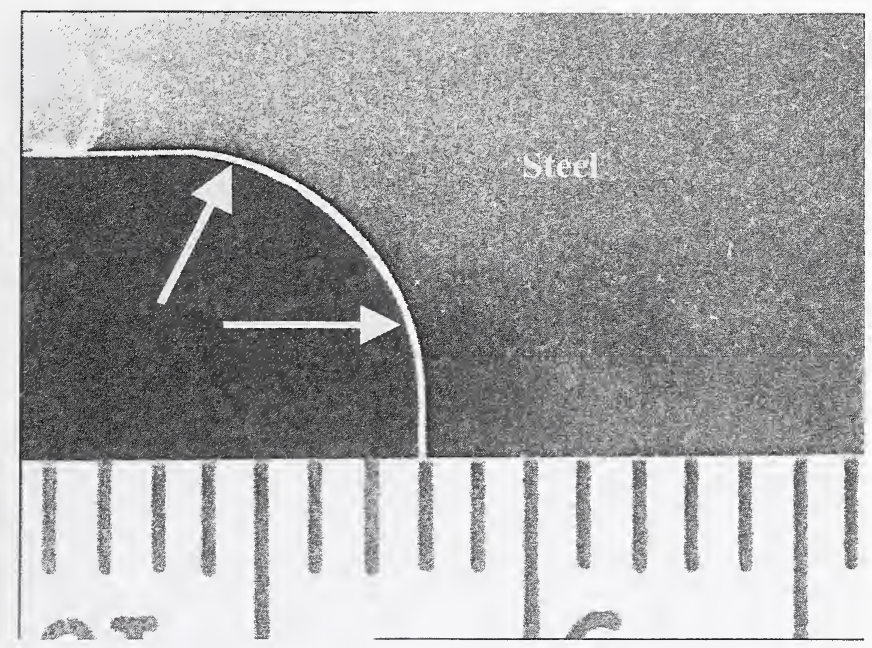

Figure 7: The "old" pins had a large $(4.76 \mathrm{~mm})$ radius, helpful in avoiding a high stress concentration at the change in cross-sectional area associated with the shank-to-head transition. The scale is in millimeters.

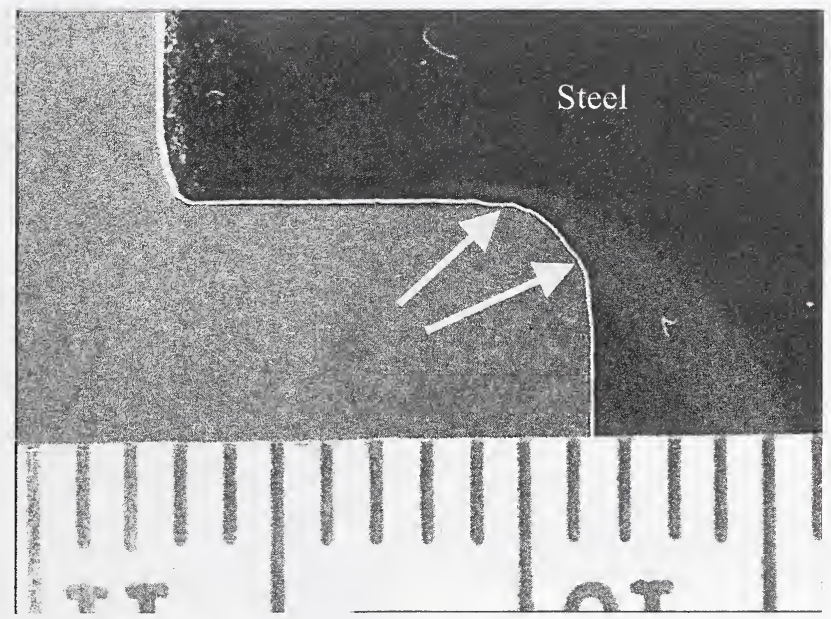

Figure 8: The "new" pins had a smaller ( 1.9 to $2.9 \mathrm{~mm})$ radius at the shank-to-head transition, clearly increasing the stress concentration associated with this transition. The scale is in millimeters. 


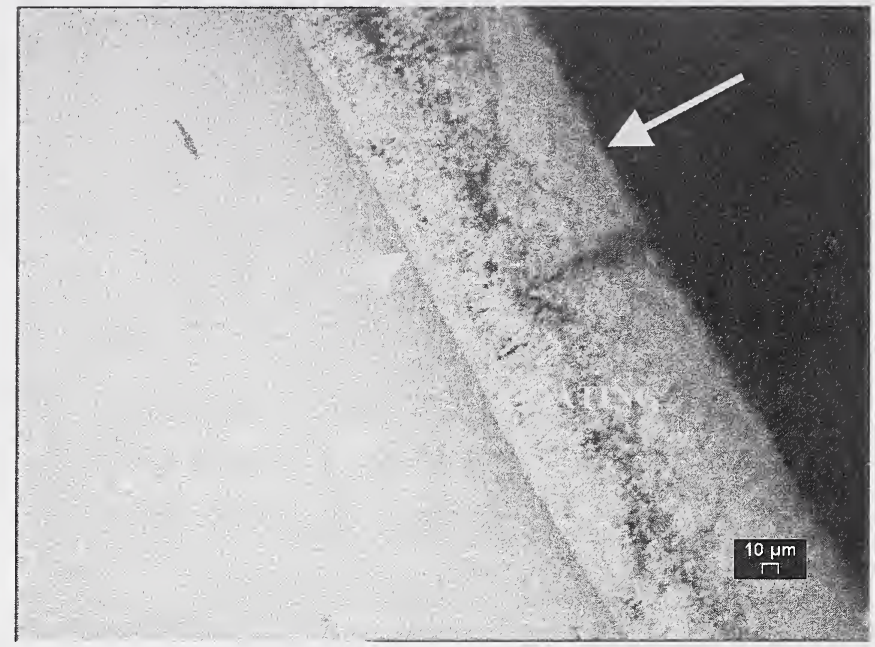

Figure 9: The coating layer on the old pins was approximately $100 \mu \mathrm{m}$ thick. This coating is typical of those found for steel that has been hot-dip galvanized.

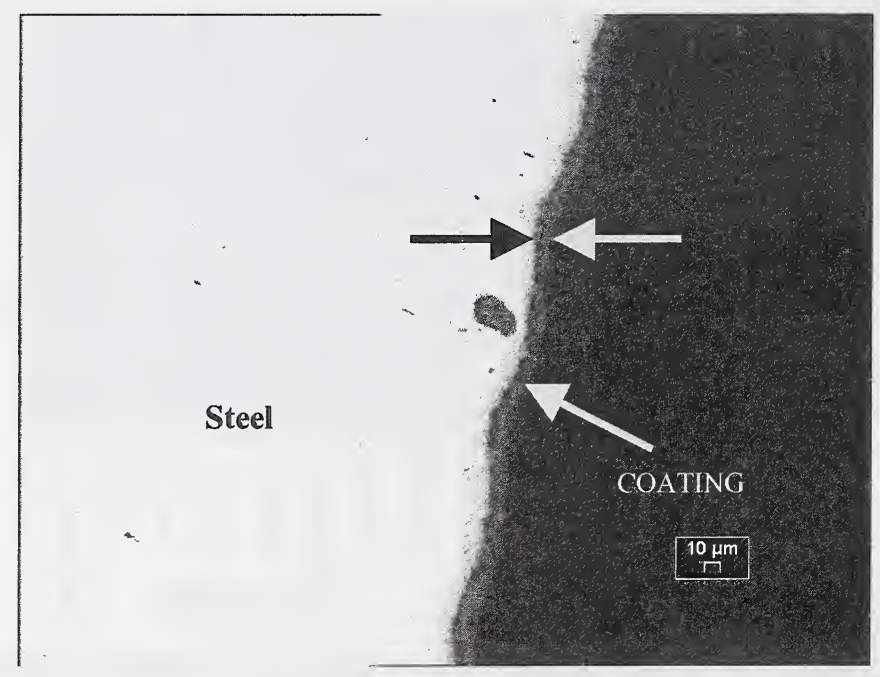

Figure 10: The new pins have a $10 \mu \mathrm{m}$ thick electroplated zinc coating (dark band). Note the dark oblong imperfection just below the surface of the pin. 


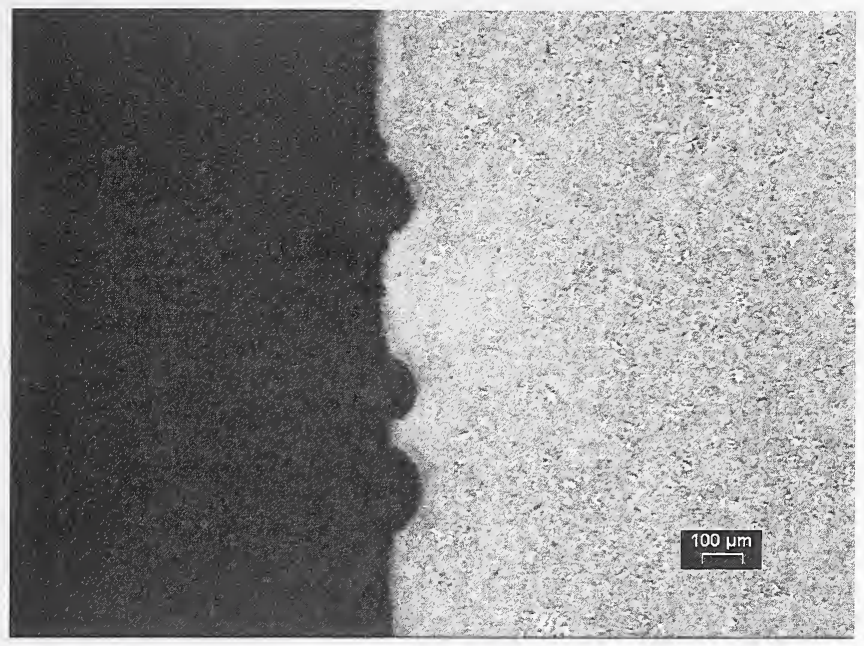

Figure 11: In some regions, the new pins had pits, shown here in the cross section. These particular flaws were found adjacent to the radius at the head of the pin.

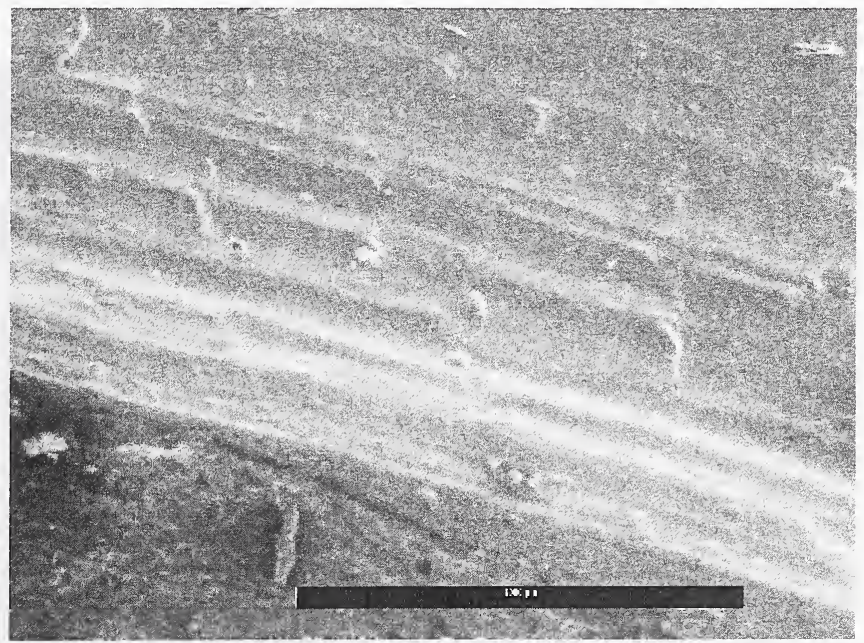

Figure 12: Here, more of the outside surface of the failed pin is visible, in the region where the fatigue cracking initiated. The grooves from the machining shown here were typical of those found on the sample. The length of the scale bar is $1000 \mu \mathrm{m}$. 


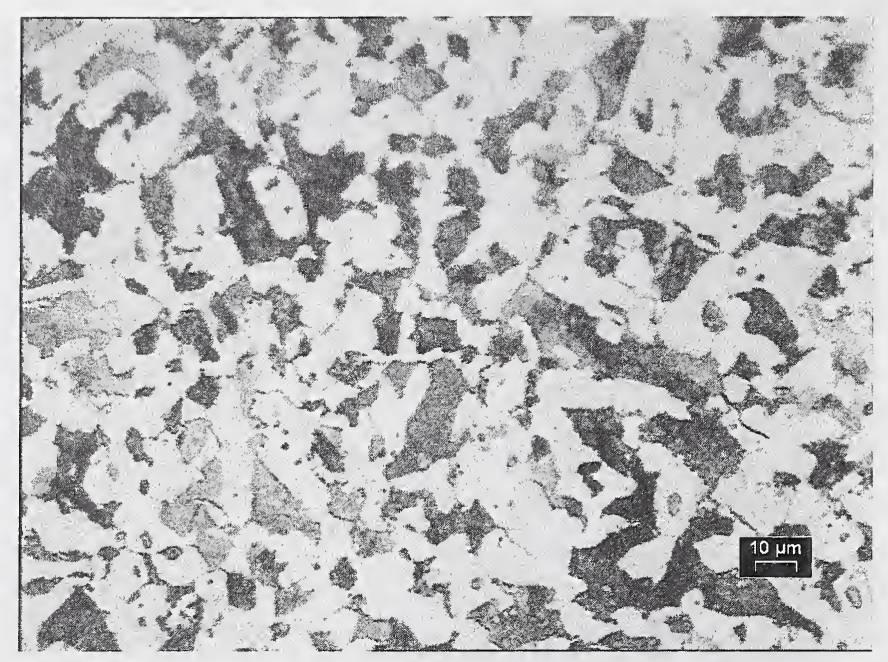

Figure 13: The steel used for the old pins was a plain carbon steel (AISI 1030). The microstructure of the steel was found to be a mixture of ferrite and pearlite, as might be expected. The grain size was not quantified, but as shown here, it is reasonably small (10 to 20 $\mu \mathrm{m})$ and was found to be uniform across the pin we examined.

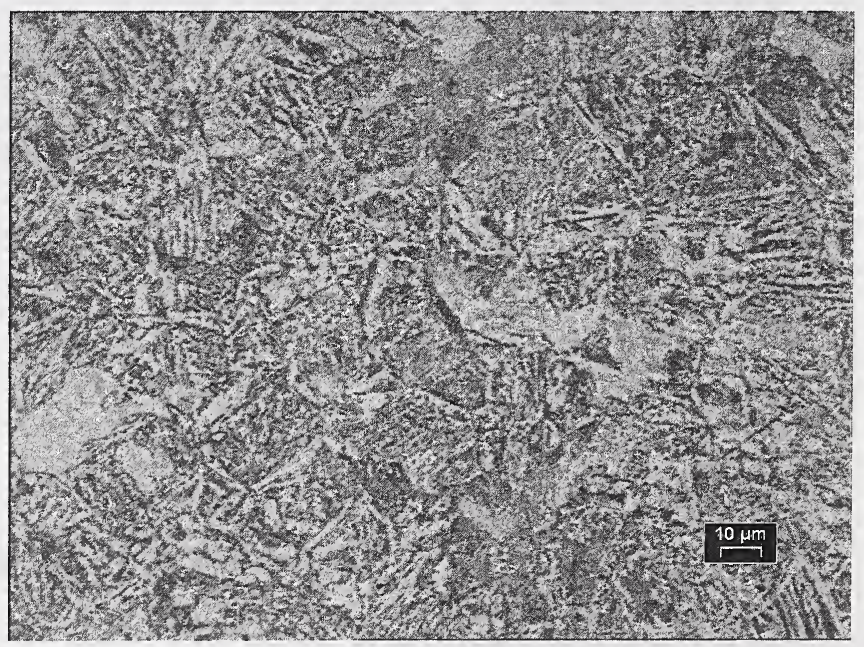

Figure 14: The steel used for the new pins, seen here, is an alloy steel (AISI 4140). The microstructure appears to be a mixture of ferrite plates (light) and upper bainite with some pearlite (dark regions). 


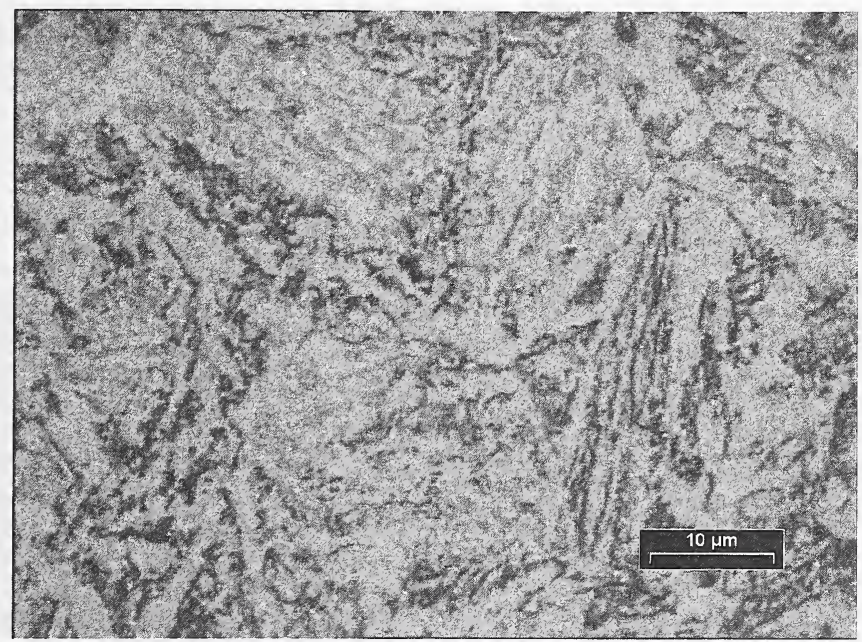

Figure 15: The AISI 4140 steel, at higher magnification than in figure 14, shows the microstructural constituent more clearly. In many regions (not necessarily here) the carbide phase in the bainite (and pearlite) appears to be spheroidized.

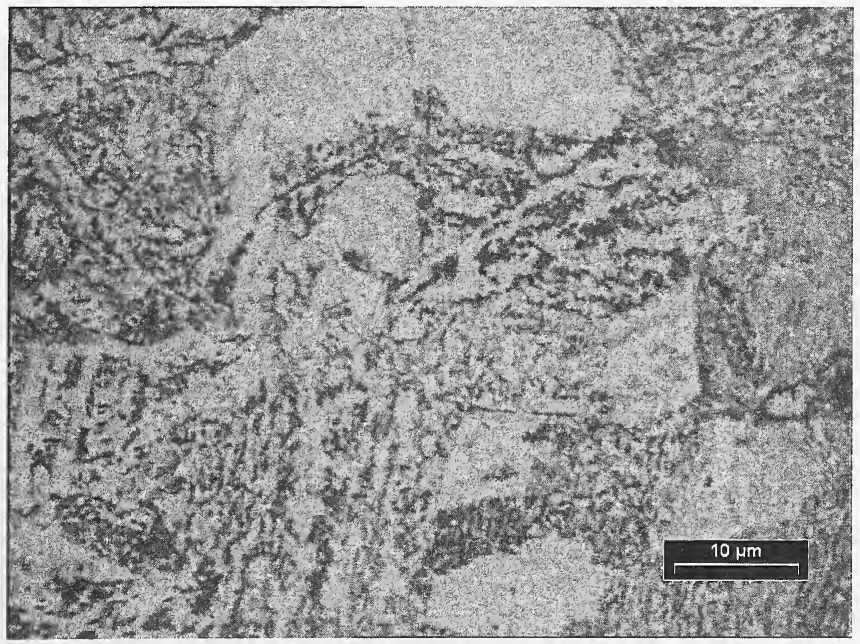

Figure 16: Microstructure of the AISI 4140 steel showing features similar to those shown in figure 15, but from a different location in the cross section of the sample. The microstructure was quite uniform throughout the cross section of the pin we examined. 


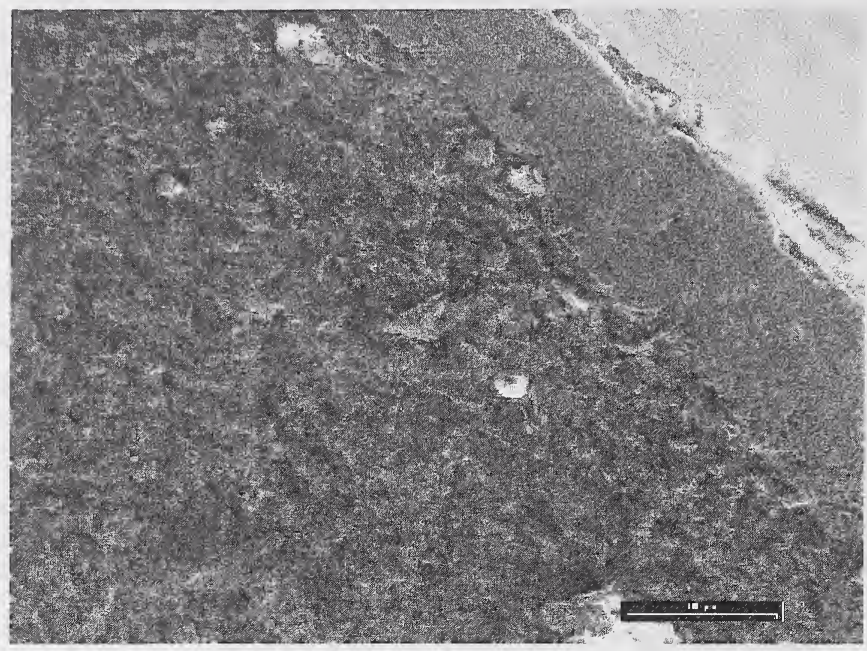

Figure 17: Starting at the upper right-hand corner, the outside surface of the pin is shown, then a darker band that is likely a ridge of zinc plating near the origin of the fatigue crack (the top edge of the zinc was probably deformed following the failure), then the appearance of the fatigue-crack surface. The length of the scale bar is $100 \mu \mathrm{m}$.

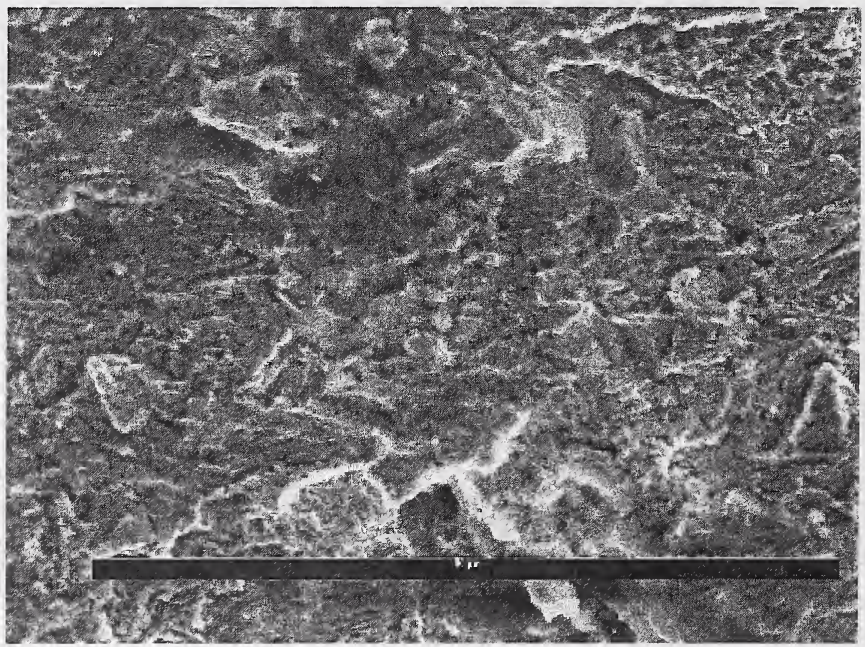

Figure 18: The surface of the fatigue crack has a complex and very fine structure, which reflects the microstructure of the steel. The length of the scale bar is $100 \mu \mathrm{m}$. 


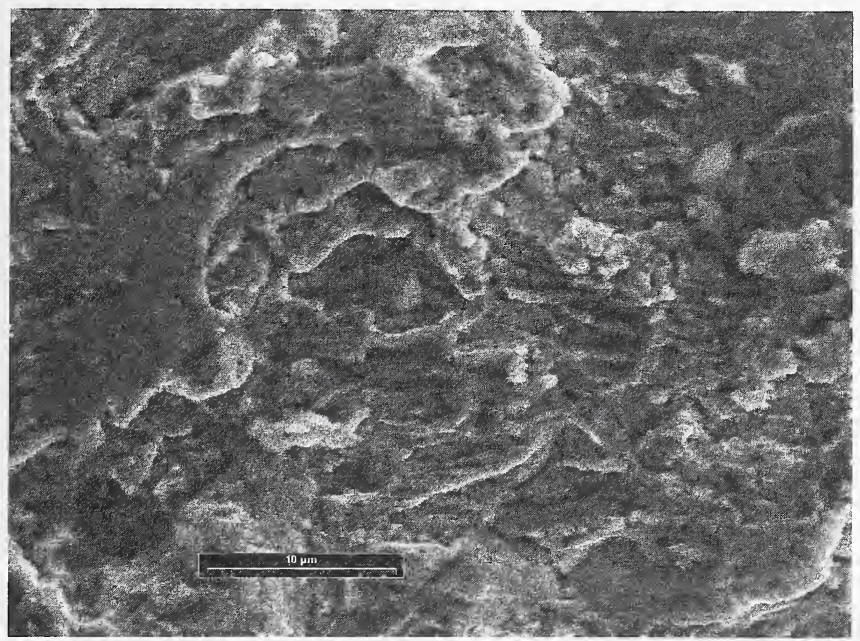

Figure 19: At slightly higher magnification, the nature of the torturous path of the fatiguecrack is even more evident. The length of the scale bar is $10 \mu \mathrm{m}$.

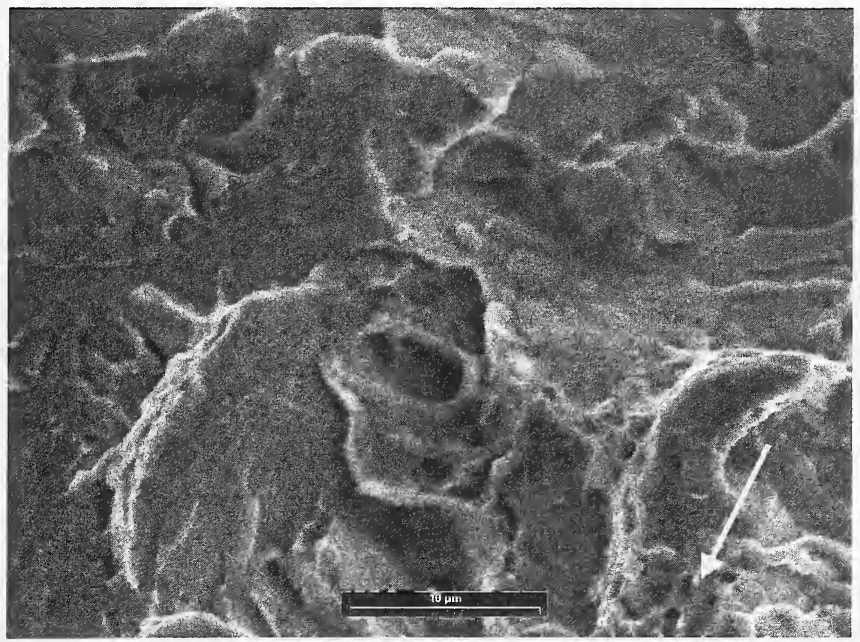

Figure 20: The overload regions of the pin failed in a brittle manner by a quasi-cleavage mechanism. The yellow arrow points to a local area of more ductile fracture and ductile dimples. The scale bar is $10 \mu \mathrm{m}$ in length. 


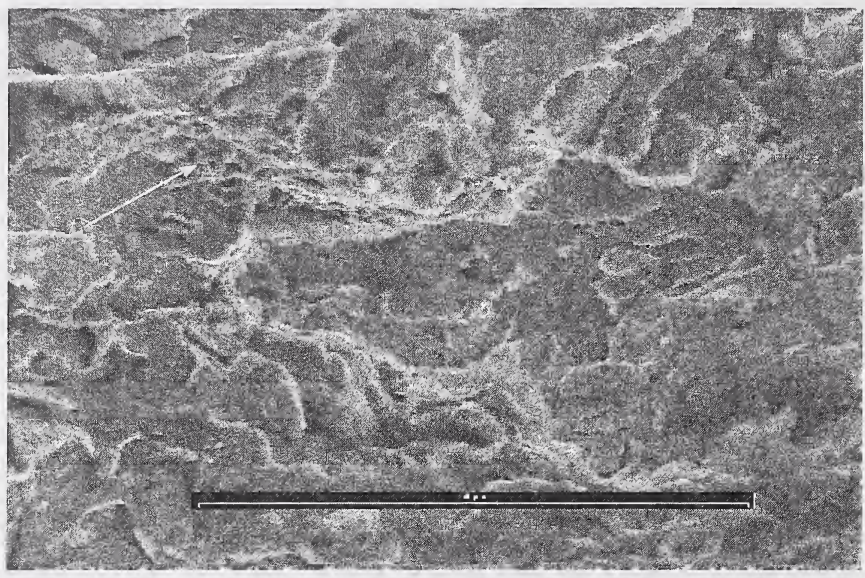

Figure 21: Another example of the classical quasi-cleavage-like appearance of the fracture surface of the pin in the overload region of the pin that failed in service. The arrow points to local ductile dimpling. The length of the scale bar is $50 \mu \mathrm{m}$.

\section{Effects of Stress Concentrations}

The following explains the failure in terms of the concepts of high-cycle fatigue failure theory called the "stress-life approach" as developed by Norton in Machine Design [5].

A change in cross-sectional geometry, such as the radius in a bolt body-to-head transition concentrates applied stress. Geometric changes (intentional or otherwise) in a part are often called "stress-raisers." The amount of stress concentration in any particular geometry is denoted by a geometric stress-concentration factor, $\mathrm{K}_{\mathrm{t}}$, for normal stresses. The maximum stress at a local stress-raiser is then defined as

$$
\sigma_{\max }=K_{t} \sigma_{n o m},
$$

where $\sigma_{\text {nom }}$ is the nominal stress calculated for the particular applied loading and net cross section assuming a stress distribution across the section that would be obtained for a uniform geometry. The factor $\mathrm{K}_{\mathrm{t}}$ takes only the effects of part geometry into account and does not consider how the material behaves when subjected to stress concentrations. The theoretical stress-concentration factor for a rod with a shoulder fillet is given by 


$$
K_{t}=A\left(\frac{r}{d}\right)^{b}
$$

where $d$ is the body diameter, $r$ is the radius at the transition, and the coefficient $A$ and the exponent $b$ are found in the table in Figure C.1. Knowing the geometry of the axially loaded pin, we can use the figure in Figure C.1 to determine the theoretical stress-concentration factor. The stress-concentration factor at the radius for the AISI 1030 pin with a radius of $4.8 \mathrm{~mm}$ ( 0.1875 in) is found to be 1.73 , and the stress-concentration factor for the AISI 4140 steel with a radius of only $1.9 \mathrm{~mm}(0.07 \mathrm{in})$ is $2.29,32 \%$ higher than a stress of 1.73 .

The ductility or brittleness of the material, along with the type of loading (static or dynamic) affects how the material responds to stress concentrations. The type of loading applied to the pin in this study is considered dynamic. In addition to the static load (preload) applied to the guy wires, (therefore the pin), the winds applied variable loads to the tower, wires and pins as well. Stress-concentration factors should be applied to both brittle and ductile materials when dynamic loads are present. There are, however, material-related parameters to consider. Stress concentrations affect all materials under dynamic loads, some materials more than others. The sensitivity of material to stress concentrations is referred to as notch sensitivity. The parameter $\mathrm{q}$ is used to denote a material's sensitivity to the stress concentration. Generally, ductile materials are less notch-sensitive, while brittle materials are more notch-sensitive. However, ductility (as measured by tensile testing) is not a measure of immunity to stress concentration in fatigue. Therefore notch sensitivity, $q$, can be defined as

$$
q=\frac{K_{f}-1}{K_{t}-1}
$$

where $K_{t}$ is the theoretical (static) stress-concentration factor for the particular geometry and $K_{f}$ is the fatigue (dynamic) stress-concentration factor. The practical measure of notch sensitivity in a material is the factor of stress concentration for fatigue, $\mathrm{K}_{\mathrm{f}}$. This equation can be rewritten to solve for $K_{f}$

$$
K_{f}=1+q\left(K_{t}-1\right) \text {. }
$$

Notch sensitivity can also be defined in terms of Neuber's constant $a$ (found in Table C.1) and the notch radius $r$, both expressed in inches 


$$
q=\frac{1}{1+\frac{\sqrt{a}}{\sqrt{r}}} .
$$

To find the dynamic stress-concentration factor $\mathrm{K}_{\mathrm{f}}$, we first determine the theoretical stress concentration $\mathrm{K}_{\mathrm{t}}$ for the particular geometry and loading; then establish the appropriate notch sensitivity for the chosen material and use them in (4) above. The nominal dynamic stress is then increased by the factor $\mathrm{K}_{\mathrm{f}}$ as was done for the static situation

$$
\sigma=K_{f} \sigma_{n o m}
$$

To determine the fatigue stress-concentration factor, $\mathrm{K}_{\mathrm{f}}$, in the old AISI 1030 carbon steel pin with a $4.8 \mathrm{~mm}(0.1875 \mathrm{in})$ radius in the cross-sectional change between the head and body, we must first find the static stress-concentration factor $\mathrm{K}_{\mathrm{t}}$ and the notch sensitivity factor $\mathrm{q}$. The diameters of the head and body are, respectively, $54.7 \mathrm{~mm}$ (2.155 in) and $38.1 \mathrm{~mm}(1.5 \mathrm{in})$. Substituting known variables in (2), (4) and (5) above, we obtain a $\mathrm{K}_{\mathrm{f}}$ of 1.73.

Using the same equations, we calculate $\mathrm{K}_{\mathrm{f}}$ for the new AISI 4140 alloy steel pins with respective head and body diameters of $55.4 \mathrm{~mm}(2.18 \mathrm{in})$ and $38.1 \mathrm{~mm}(1.5 \mathrm{in})$, and radii that varied from $1.9 \mathrm{~mm}(0.07 \mathrm{in})$ to $2.9 \mathrm{~mm}(0.11 \mathrm{in})$. The less severe radius was the $2.9 \mathrm{~mm}$ radius with a $\mathrm{K}_{\mathrm{f}}$ of 2.05 . The sharper radius, measured at $1.9 \mathrm{~mm}(0.07 \mathrm{in})$, had a $\mathrm{K}_{\mathrm{f}}$ of 2.13.

To demonstrate the effect of $\mathrm{K}_{\mathrm{f}}$, we suppose that a nominal tensile stress of $138 \mathrm{MPa}$ (20 ksi) was applied to the pin in the axial direction, and the head of the pin supported the load. Using the above fatigue stress-concentration factors $\mathrm{K}_{\mathrm{f}}$, we have

AISI 1030 pin: $1.73 * 138 \mathrm{MPa}=239 \mathrm{MPa}(35 \mathrm{ksi})$ effective stress AISI 4140 pin: $2.05 * 138 \mathrm{MPa}=283 \mathrm{MPa}(41 \mathrm{ksi})$ effective stress AISI 4140 pin: $2.13 * 138 \mathrm{MPa}=294 \mathrm{MPa}(43 \mathrm{ksi})$ effective stress

The estimated fatigue endurance limit $S_{e^{\cdot}}\left(10^{6}\right.$ cycles $)$ of a material is

$$
S_{e^{\prime}} \cong 0.5 S_{u t},
$$

where $S_{u t}$ is ultimate tensile stress, and is based on fatigue of smooth, polished samples. The estimated fatigue endurance limits for AISI 4140 and AISI 1030 steels in this report are 498 
$\mathrm{MPa}(72 \mathrm{ksi})$ and $279 \mathrm{MPa}(40 \mathrm{ksi})$, respectively, using data for ultimate tensile strength generated earlier in this report.

Therefore, an endurance limit, corrected for physical differences between polished test specimens and the part actually in use, must be calculated. In addition, other factors taken into account are differences in environmental effects and type of loading. These factors, and others, are incorporated into a set of strength-reduction factors [5] that are multiplied by the estimated fatigue-endurance limit to obtain a corrected endurance limit $S_{e}$, for a particular application:

$$
S_{e}=C_{\text {load }} C_{\text {size }} C_{\text {surface }} C_{\text {temp }} C_{\text {reliability }} S_{e^{\prime}},
$$

where $C_{\text {load }}$ is a strength-reduction factor that takes into account the loading type (axial or torsional) and is $\mathbf{0 . 7 0}$ for axial loading conditions; $C_{\text {size }}$ is a size factor that takes into account the fact that larger parts fail at lower stresses due to the higher probability of a flaw being present in a larger stressed volume, and is $0.869 d^{-0.097}$ for this $38 \mathrm{~mm}$ (1.5 in) diameter bar, where $d$ is the bar diameter; $C_{\text {surface }}$ is a strength reduction factor that takes into account the surface imperfections that serve as stress raisers and is 0.32 for this pitted, forged, rough machined part; $C_{\text {temp }}$ is a factor that takes into account the effect of high temperature on the fatigue strength of the part and is 1 for this ambient-temperature part; $C_{\text {reliability }}$ takes into account the scatter in multiple test data and for a desired $99.99 \%$ probability that this part will meet or exceed assumed strength (assuming $8 \%$ standard deviation); the reliability factor is $0.702 ; S_{e}$ is the estimated fatigue endurance limit $498 \mathrm{MPa}$, as calculated earlier for our AISI 4140 steel.

Substituting the known factors in (8) for the AISI 4140 forged pin,

$$
S_{e}=(0.70)(0.9746)(0.32)(1)(0.702)(498)
$$

we have a corrected fatigue endurance limit of $76 \mathrm{MPa}(11 \mathrm{ksi})$. Note that this is well below the estimated fatigue endurance limit (498 MPa). Of more importance is to note that if this part were needed to survive $10^{6}$ cycles, the stresses must not exceed $76 \mathrm{MPa}(11 \mathrm{ksi})$.

The corrected fatigue endurance limit for the AISI 1030 steel is found by substituting known factors

$$
S_{e}=(0.70)(0.9746)(0.75)(1)(0.702)(279)
$$

to give us $100 \mathrm{MPa}(14.5 \mathrm{ksi})$. Note that this is above the corrected fatigue endurance limit for the AISI 4140 steel. This is due mainly to the surface-finish factor assigned to the 4140 steel because of the "as forged" finish (pitted surface and circumferential grooves due to poor machining). In other words, the finish on the AISI 1030 steel pins more than offsets its lower static strength, giving it a service load higher than that for the AISI 4140 steel pins. 
Using the above information, we can construct a Goodman diagram (fig. 22), a conservative, commonly used failure criterion for parts subjected to both mean and alternating stresses.

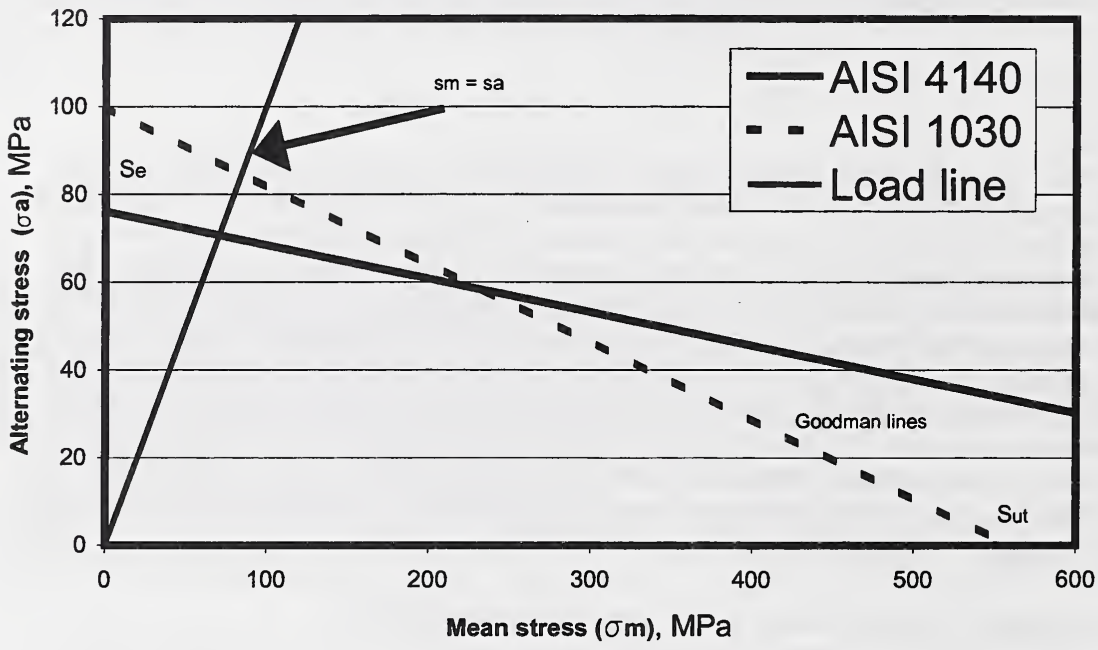

Figure 22: Goodman diagram for AISI 1030 and AISI 4140 steel pins. Arrow shows load line where alternating stress is equal to mean stress.

The two axes of the diagram are alternating $\left(\sigma_{\mathrm{a}}\right)$ and mean $\left(\sigma_{\mathrm{m}}\right)$ stresses. The Goodman line is drawn for both AISI 1030 and AISI 4140 steels. These lines intersect $S_{e}$ on the $\sigma_{\mathrm{a}}$ axis and the $S_{u t}$ on the $\sigma_{\mathrm{m}}$ axis. The "load-line" pointed out by the arrow, assumes the condition where mean stress is equal to the alternating stress. If the plotted stress stays below the material curves, then the respective material should last for more than $10^{6}$ cycles.

Since we have no actual loading data on the pins, we can only make an educated guess in stating that the load is alternating somewhere between a maximum point (less than ultimate load) and zero (since the pins in this application cannot be loaded in compression). This means that the alternating $\left(\sigma_{a}\right)$ and mean stress $\left(\sigma_{m}\right)$ will lie on the $\sigma_{a}=\sigma_{m}$ line, pointed out by the arrow in figure 22 above. The factor of safety is determined by dividing the distance from the origin to the failure line (Goodman line) by the distance from the origin to the effective stress. 
For example, we suppose the nominal stress in the pin is $40 \mathrm{MPa}(5.8 \mathrm{ksi})$ and this nominal stress is multiplied by the $K_{f}$ of 2.13 for the AISI 4140 steel pin with a sharp radius. The effective stress would be $85 \mathrm{MPa}(12.3 \mathrm{ksi})$. This lies clearly above the failure line of the Goodman diagram, and would result in a short lifetime for the pin. If we use the same stress for the AISI 1030 steel, with a $K_{f}$ of 1.73 , we would have an effective stress of $69 \mathrm{MPa}(10.0$ $\mathrm{ksi}$ ). This lies below the failure line for the AISI 1030 steel pin and would result in a long life for the pin. The factors of safety for the 1030 and 4140 pins are 1.23 and 0.82 , respectively. This example demonstrates the advantage of the well machined 1030 steel over the poorly machined 4140 steel, if we assume that the wind load goes from zero to a maximum level.

\section{Summary and Conclusions}

In our opinion, the AISI 4140 steel was an acceptable choice of material to replace the AISI 1030 steel, although some might argue that it is not a "carbon steel" as specified on the drawing. The point we would like to make here, however, is that the simple specification of carbon steel along with a minimum strength was not adequate to ensure an appropriate choice of material for the pin. A carbon steel could have been processed to meet the minimum strength requirement and yet be so brittle, for example, that it would be unsuitable for the pin. So, the AISI 4140 steel was a reasonable choice (as was carbon steel), but adequate specifications were needed to ensure a material suitable for service. In addition, the drawings supplied to the fabricator called out for a smaller radius than that used in the original pins, and there were no tolerances or finishes called out on the finished pins. All of this resulted in pins that were machined according to the drawings, but were inferior to the original pins. The new pins had radii that varied in dimension (all too sharp), had circumferential tool marks in the radius, and had pitting in the radius from an unknown source, all resulting in a lower fatigue life than originally planned.

We conclude that the AISI 4140 steel pin failed due to fatigue-crack growth that initiated in the fillet of the radius between the head and body of the pin. Localized stresses at pits, machining marks, and other surface flaws likely aided in the initiation of the fatigue crack.

\section{Recommendations}

New pins should be fabricated from proper drawings calling out dimensional tolerances, surface finishes, a generous radius in the fillet (within limits specified for the specific insulator washer), appropriate heat-treatment to optimize properties for toughness and fatigue strength, and a plating process that does not degrade the surface or integrity of the pins. If new pins are forged from AISI 4140, before being machined, the pins should be normalized, hardened, and tempered to between 28 and $32 \mathrm{HRC}$ to increase fatigue strength. The microstructure should be $100 \%$ tempered martensite and the prior austenite grain size should be reasonable. In order to minimize the chance of hydrogen embrittlement and pitting, we recommend that the pins not be pickled prior to plating. However, pickling may be used if appropriate guidelines, such as those recommended in ASTM A143-01 [6], are closely followed. 


\section{References}

[1] Personal communication, Bob McClellan; June 21, 2001.

[2] ASM Metals Handbook, $9^{\text {th }}$ Edition, Vol. \# 1, Properties and Selection: Irons and Steels, Metals Park, OH: ASM Int.; 1988. p. 456.

[3] ASM Metals Handbook, $9^{\text {th }}$ Edition, Vol. \# 11, Failure Analysis and Prevention: Irons and Steels, Metals Park, OH: ASM Int.; 1988. p. 26.

[4] ASM Metals Handbook, $8^{\text {th }}$ Edition, Vol. \# 10, Failure Analysis and Prevention: Irons and Steels, Metals Park, OH: ASM Int.; 1975. p. 299.

[5] Norton, R.L., Machine Design, New Jersey: Prentice-Hall; 1998. 1048 p.

[6] American Society for Testing and Materials, Vol \# 1.06, ASTM Standard Practice for Safeguarding Against Embrittlement of Hot-Dip Galvanized Structural Steel Products and Procedure for Detecting Embrittlement, West Conshohocken, PA: ASTM Int.; 2002 
Appendix A. Insulator pin drawings

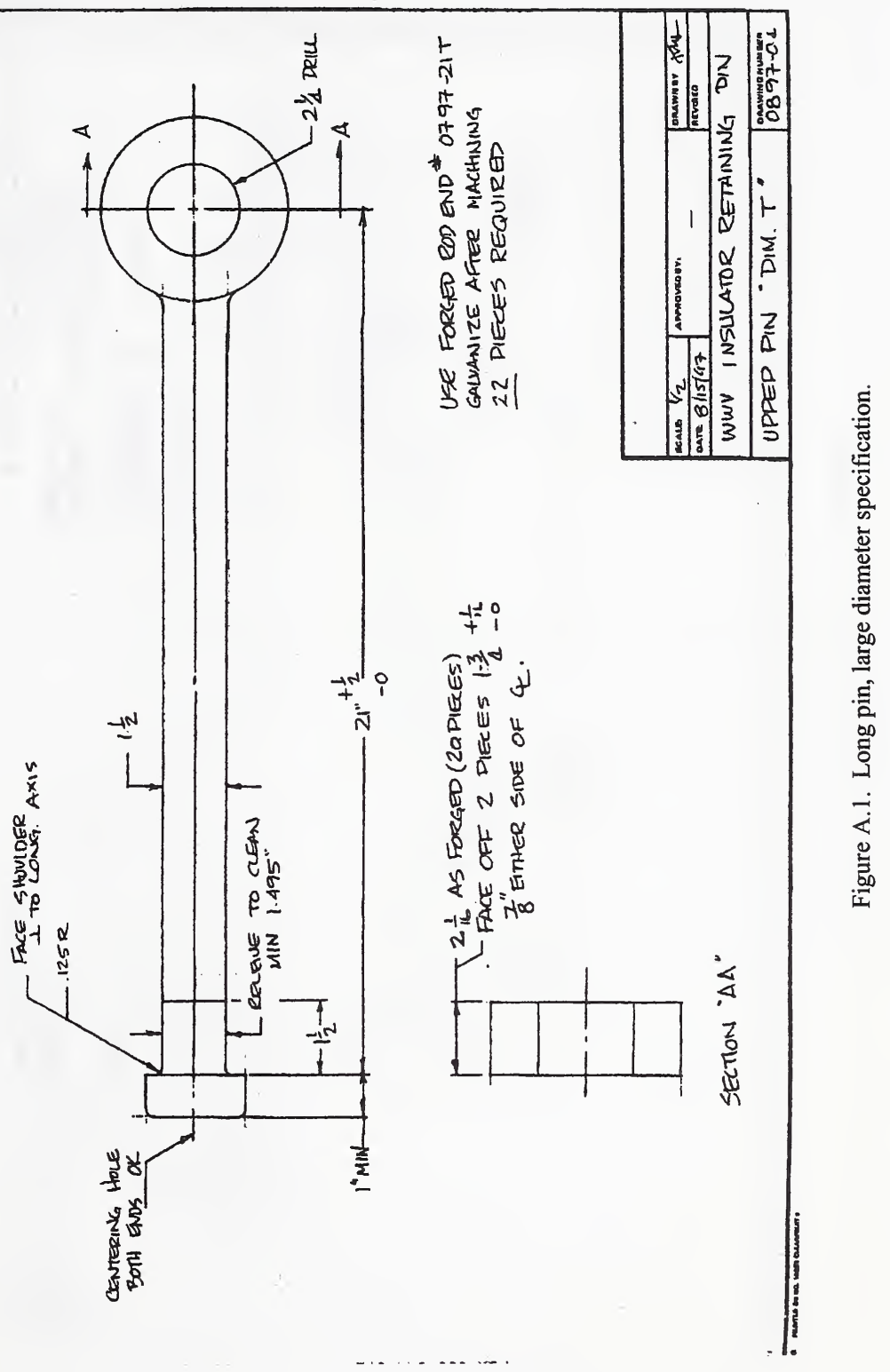




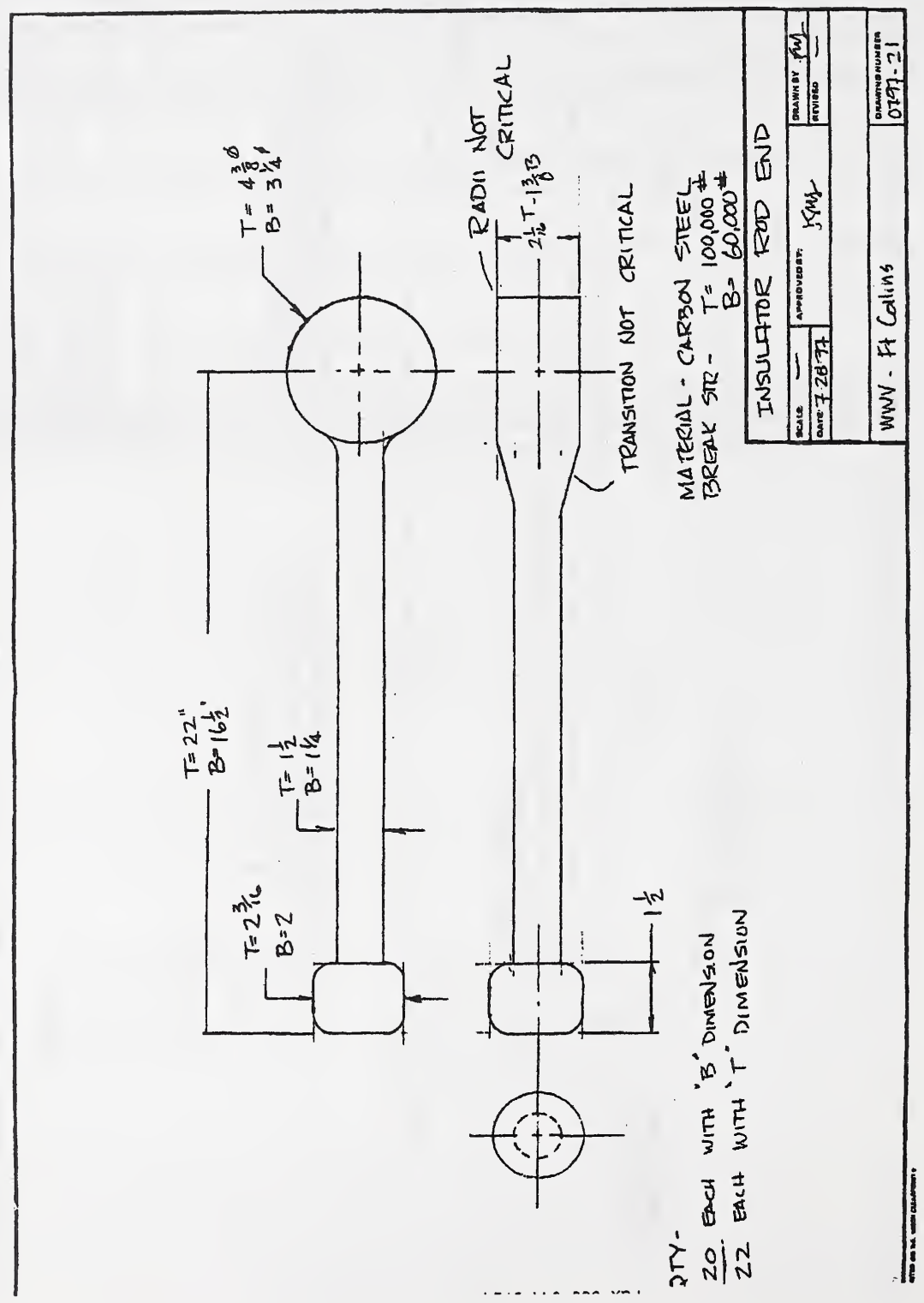

है 


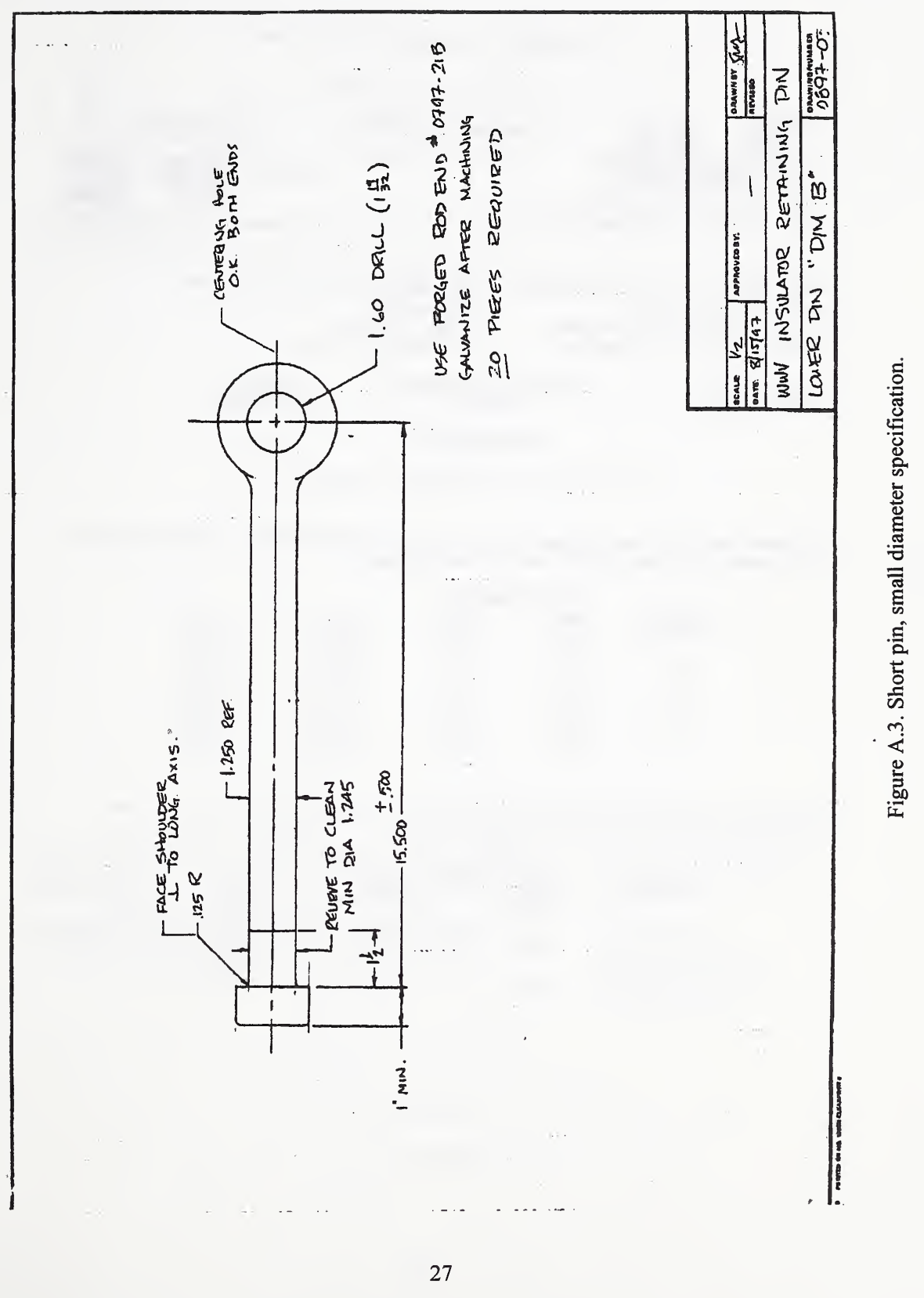


Appendix B. Chemical analysis of pins
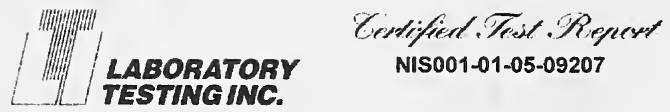

2331 Topaz Drive, Hatfield, PA 19440

TEL: 800-219-9095 - FAX: 800-219-9096

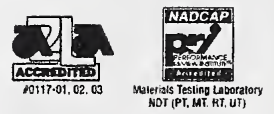

\section{SOLD TO}

NATIONAL INSTITUTE OF STANDARD ACCTS PAYABLE OFFICE

100 BUREAU DRIVE, STOP 5203

GAITHERSBURG, MD 20899-5203

\section{SHIP TO}

NATIONAL INSTITUTE OF STANDARD

325 Broadway

Boulder, CO 80303

ATTN: David McColskey

\section{CUSTOMER P.O. CREDIT CARD \\ CERTIFICATION DATE 05/03/01 \\ SHIP VIA \\ FAX AND MAIL \\ DESCRIPTION}

3 pcs. Test Samples, Identified as N1, N2 and G1

The referenced sample was submitted to chemical content evaluation and (2) pieces were found to be in conformance to UNS G41400 with the following results:

\begin{tabular}{|c|c|c|c|c|}
\hline \multirow[b]{2}{*}{ ELEMENT } & \multicolumn{2}{|c|}{ REQUIREMENTS } & \multirow[b]{2}{*}{ N1 } & \multirow[b]{2}{*}{ N2 } \\
\hline & MIN & MAX & & \\
\hline $\mathrm{C}$ & $\overline{0.38}$ & $\overline{0.43}$ & $0 . \overline{39} \%$ & $0 . \overline{41} \%$ \\
\hline $\mathrm{Cr}$ & 0.80 & 1.10 & $0.97 \%$ & $0.95 \%$ \\
\hline $\mathrm{Mn}$ & 0.75 & 1.00 & $0.93 \%$ & $0.98 \%$ \\
\hline Mo & 0.15 & 0.25 & $0.19 \%$ & $0.16 \%$ \\
\hline$P$ & 0.000 & 0.035 & $0.010 \%$ & $0.010 \%$ \\
\hline $\mathrm{Si}$ & 0.15 & 0.35 & $0.22 \%$ & $0.23 \%$ \\
\hline $\mathrm{s}$ & 0.000 & 0.040 & $0.031 \%$ & 0.028 \\
\hline
\end{tabular}

The referenced sample was submitted to chemical content evaluation and it was found to be in conformance to UNS G10300 with the following results:

\begin{tabular}{|c|c|c|c|}
\hline \multicolumn{4}{|c|}{ REQUIREMENTS } \\
\hline ELEMENT & MIN & MAX & G1 \\
\hline $\mathrm{C}$ & $\overline{0.28}$ & $\overline{0.34}$ & $0 . \overline{30} \%$ \\
\hline $\mathrm{Mn}$ & 0.60 & 0.90 & $0.77 \%$ \\
\hline P & 0.000 & 0.040 & $0.011 \%$ \\
\hline $\mathrm{Si}$ & & & $0.184 \%$ \\
\hline s & 0.000 & 0.050 & $0.020 \%$ \\
\hline
\end{tabular}




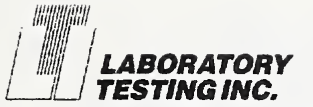
Cretigied. Tejt Prepert
NIS001-01-05-09207

2331 Topaz Drive, Hatfield, PA 19440

TEL: $800-219-9095$ - FAX: $800-219-9096$

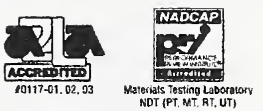

A Qualitative Plating Identification was performed on (3) pieces of the submitted Test Specimens and it revealed the plating to appear to be Zinc.

The services performed above were done in accordance with LTI's Quality System Program Manual Revision 15 dated $12 / 4 / 00$ These results relate only to the items tested and this report shall not be reproduced, except in full, without the written approval of Laboratory Testing, Inc. L.T.I. is accredited by A2LA in the Chemical, Mechanical and Nondestructive Fields of Testing. L.T.I. is accredited by NADCAP in the Matenal's Testing and NDT, MT, PT, RT and UT.

MERCURY CONTAMINATION: During the testing and inspection, the product did not come in direct contact with mercury or eny of its compounds nor with any mercury containing devices employing a single boundary of containment.
Sherri L. Lengyel

QA Coordinator Sheni d. Eengyed

By:

Authorized Signature

Page 2 of 2 
Appendix C. Stress concentration factors

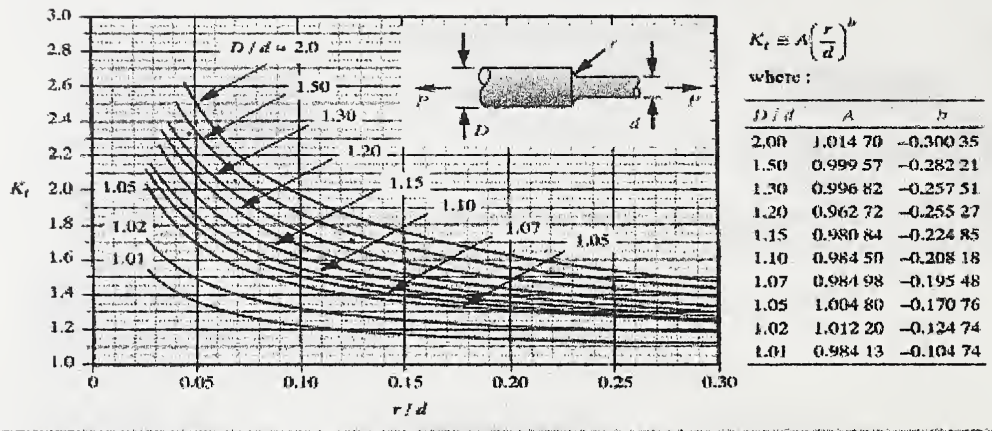

Geometoris Stress-Concontration Factos $k_{1}$ for a Shaft with a Shouldar Fiflet in Axial tencion

Figure C.1. Stress concentration factors for a shaft with a shoulder fillet in axial tension.

Table C.1. Neuber's Constant for Steels

\begin{tabular}{lc}
\hline $\mathrm{S}_{\mathrm{ut}}(\mathrm{ksi})$ & $\sqrt{\mathrm{a}\left(\text { in }^{0.5}\right)}$ \\
\hline 50 & 0.130 \\
55 & 0.118 \\
60 & 0.108 \\
70 & 0.093 \\
80 & 0.080 \\
90 & 0.070 \\
100 & 0.062 \\
110 & 0.055 \\
120 & 0.049 \\
130 & 0.044 \\
140 & 0.039 \\
160 & 0.031 \\
180 & 0.024 \\
200 & 0.018 \\
220 & 0.013 \\
240 & 0.009 \\
\hline
\end{tabular}



